\title{
The Evolution and Future of National Customer Satisfaction Index Models
}

\author{
Michael D. Johnson ${ }^{1}$, Anders Gustafsson ${ }^{2}$, Tor Wallin Andreassen ${ }^{3}$, Line Lervik ${ }^{3}$, Jaesung Cha $^{3}$ \\ 1: University of Michigan Business School, 701 Tappan Street, Ann Arbor, MI 48109-1234, \\ USA \\ 2: Service Research Center, University of Karlstad, 65188 Karlstad, Sweden \\ 3: Norwegian School of Management BI, P.O. Box 580, N-1301 Sandvika, Norway
}

\begin{abstract}
A number of both national and international customer satisfaction barometers or indices have been introduced in the last decade. For the most part, these satisfaction indices are embedded within a system of cause and effect relationships or satisfaction model. Yet there has been little in the way of model development. Of critical importance to the validity and reliability of such indices is that the models and methods used to measure customer satisfaction and related constructs continue to learn, adapt and improve over time. The primary goal of this research is to propose and test a number of modifications and improvements to the national index models. Using survey data from the Norwegian Customer Satisfaction Barometer (NCSB), we find general support for the proposed modifications.
\end{abstract}




\section{Introduction}

Customer satisfaction has taken on national and international significance with the development of national satisfaction barometers and indices in Sweden (Fornell, 1992), the US (Fornell, Johnson, Anderson, Cha, \& Bryant, 1996) and Norway (Andreassen \& Lindestad, 1998a). Indices have also been pilot tested in New Zealand, Austria, Korea and the European Union. It remains to be seen whether these indices will develop on a global level and, importantly, in what form. Of critical importance to the validity and reliabilityof such indices is that the models and methods used to measure customer satisfaction and related constructs continue to learn, adapt, and improve over time.

The goal of this research is to facilitate this learning, adaptation and improvement process. As a consequence of this work and in keeping with current return on quality research (Rust, Zahorik, \& Keiningham, 1995) we position customer loyalty as the key dependent variable in the model. We begin by describing customer satisfaction from an economic psychology perspective. We then describe the evolution of national satisfaction index models, including details of the models currently used in Sweden, the US, Norway and the EU. (Not included in our discussion is the Deutsche Kundenbarometer (Meyer, 1994) as it does not involve either an index or model per se.) Both the strengths and weaknesses inherent in the current approaches are discussed. We then propose a series of modifications and improvements for measuring and modeling customer satisfaction that are now incorporated into the Norwegian Customer Satisfaction Barometer (NCSB) model. The modifications are tested using data from five service industries.

\subsection{Customer satisfaction from an economic psychology perspective}

Customer satisfaction research has developed around two different types of evaluations: transaction-specific satisfaction and cumulative satisfaction (Johnson, Anderson, \& Fornell, 1995). The original interest in marketing and consumer research was on transaction-specific satisfaction, or a customer's experience with a product episode or service encounter (Yi, 1991). More recent transaction-specific research has focused on the relationship between perceived quality and satisfaction (De Ruyter, Bloemer, \& Peeters, 1997) and the role of emotions in satisfaction evaluations (Oliver, 1993).

A more economic psychology-based approach to satisfaction has grown and gained acceptance over the last decade, termed cumulative satisfaction. This approach defines satisfaction as a customer's overall experience to date with a product or service provider (Johnson \& Fornell, 1991). This definition is consistent with those in both economic psychology (Warneryd, 1988) and welfare economics (Simon, 1974) where customer satisfaction is synonymous with the concept of consumption utility. An important advantage of the cumulative satisfaction construct over a more transaction-specific view is that it is better able to predict subsequent behaviors and economic performance (Fornell et al., 1996; Johnson et al., 1995). This is because customers make 
repurchase evaluations and decisions based on their purchase and consumption experience to date, not just a particular transaction or episode.

Viewing satisfaction as a form of consumption utility is also consistent with Poiesz and von Grumbkow's (1988) general framework for understanding economic "well-being". This framework views economic well-being as one component of an individual's overall quality of life. Other domains include evaluations of health, socio-cultural context, political freedom and stability. Economic well-being is itself composed of three sub-components, job satisfaction, income evaluation, and consumer or customer satisfaction. At an aggregate level, Poiesz and von Grumbkow equate this customer satisfaction with customer welfare. It is this welfare-based or cumulative view of satisfaction upon which the prominent national satisfaction indices are built.

\section{The evolution of national satisfaction index models}

Established in 1989, the Swedish Customer Satisfaction Barometer (SCSB) was the first truly national customer satisfaction index for domestically purchased and consumed products and services (Fornell, 1992). It has historically included approximately 130 companies from 32 of Sweden's largest industries. The American Customer Satisfaction Index (ACSI) was introduced in the fall of 1994 and reports results for approximately 200 companies from 34 industries (Fornell et al., 1996). The Norwegian Customer Satisfaction Barometer (Andreassen \& Lervik, 1999; Andreassen \& Lindestad, 1998a) was introduced in 1996 and, as of 1999, reports results for 42 companies in 12 different industries (both business-to-consumer and business-to- business). The most recent development among indices is a pilot test of the European Customer Satisfaction Index (ECSI) across four industries and 11 countries in the European Union (Eklof, 2000).

In reviewing the national indices, we pay particular attention to the ACSI model specification. This model is an evolution of the original Swedish model, has been adopted on a smaller scale in New Zealand and Taiwan (Fornell et al., 1996) and Austria (Hack1, Scharitzer, \& Zuba, 1996), and is the basis for the models being used in Norway and the EU. A critical evaluation of the model is, therefore, important to develop the best possible model specification.

It should be noted that treating satisfaction as an overall evaluation of the consumption experience resolves certain modeling issues. Consider that while some studies find that satisfaction drives a general perception of quality, others find that perceptions of quality drive satisfaction (De Ruyter et al., 1997). Clearly, however, if satisfaction is defined as an overall evaluation of performance to date, more recent quality received is necessarily an antecedent to satisfaction (Johnson et al., 1995). All of the models described and proposed herein, view quality as a driver of satisfaction. 
Viewing satisfaction as a cumulative construct also dictates how one treats measures of expectancy-disconfirmation (perceived performance versus expectations). When modeling a given episode or transaction, disconfirmation is a logical antecedent to satisfaction (Oliver, 1980). In contrast, when operationalizing a customer's evaluation of their experience to date, expectancydisconfirmation is but one of several possible benchmarks that customers may use to evaluate this overall experience. Comparisons are also made to, for example, competing products, category norms and personal values, all of which should reflect cumulative satisfaction as a latent construct (Johnson \& Fornell, 1991). The solution within the national models is to operationalize satisfaction using three survey measures: overall satisfaction, expectancy- disconfirmation, and performance versus an ideal product or service in the category.

\subsection{The original SCSB}

The original SCSB model (Fornell, 1992), shown in Fig. 1, contains two primary antecedents of satisfaction: perceptions of a customer's performance experience with a product or service, and customer expectations regarding that performance. More specifically, perceived performance is equated with perceived value, or the perceived level of quality received relative to the price or prices paid. Quality per dollar or value is a common denominator that consumers use to compare brands and categories alike (Emery, 1969). The basic prediction is that as perceived value increases, satisfaction increases.

The other antecedent of

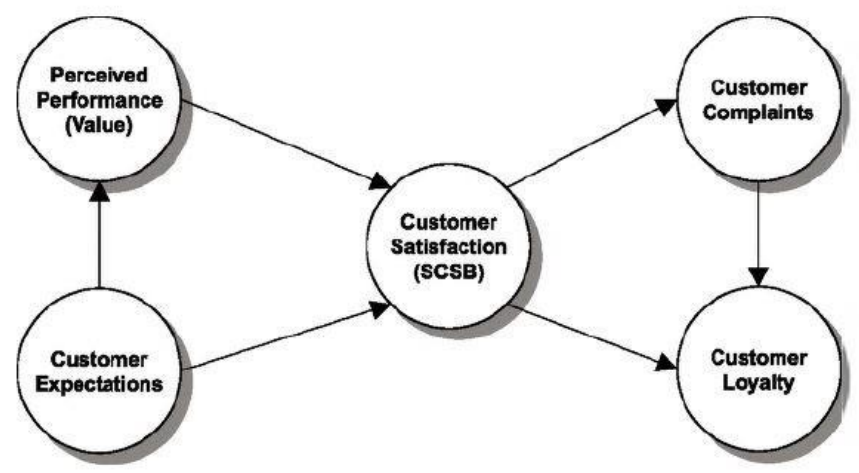
satisfaction is how well the customer expected the product or service to perform. Customer expectations are defined as that which a customer predicts ("will" expectations) rather than a normative standard or benchmark ("should" expectations; Boulding, Kalra, Staelin, \& Zeithaml, 1993). These expectations are argued to positively affect customer satisfaction because they serve as cognitive anchors in the evaluation process (Oliver, 1980). While perceived performance captures more recent experience, customer expectations capture a customer's prior consumption experience with a firm's products or services as well as advertising and word-of-mouth information. Because expectations forecast a firm's ability to provide future performance, it is argued to have a positive effect on satisfaction in the SCSB model (Fornell, 1992). Finally, expectations should be positively related to perceived performance (value). This captures customers' abilities to learn from their experience and predict the level of performance they will receive.

The consequences of satisfaction in the original SCSB model are derived from Hirschman's (1970) exit-voice theory. The theory describes situations in which a client or 
customer becomes dissatisfied with the products or services that an organization provides. The organization discovers its failure to provide satisfaction via two feedback mechanisms, exit and voice. The customer either exits or stops buying from the firm, or voices its complaint of dissatisfaction to the firm in an effort to receive restitution. Accordingly, the immediate consequences of increased satisfaction are decreased customer complaints and increased customer loyalty. An increase in satisfaction should decrease the incidence of complaints. Increased satisfaction should also increase customer loyalty (Bloemer \& Kasper, 1995), which is a customer's psychological predisposition to repurchase from a particular product or service provider. Loyalty is the ultimate dependent variable in the model because of its value as a proxy for actual customer retention and subsequent profitability.

Finally, the original SCSB includes a relationship from complaint behavior to customer loyalty. Although no prediction is made regarding this relationship, the direction and size of this relationship provides some diagnostic information as to the efficacy of a firm's customer service and complaint handling systems (Fornell, 1992). When the relationship is positive, a firm may be successfully turning complaining customers into loyal customers. When negative, complaining customers are predisposed to exit.

\subsection{The ACSI}

The ACSI model, developed in 1994 and illustrated in Fig. 2, builds upon the original SCSB model specification (for details of the ACSI survey and model see Fornell et al., 1996). The model is estimated for each of the approximate 200 firms in the survey based on a random sample of approximately 250 of the firm's customers. A total of 15 survey questions are used to operationalize the six constructs in the model. The survey questions are all rated on 1 to 10-point scales with the exception of price tolerance (described below) and complaint behavior (a dichotomous variable indicating whether the customer has complained or not). In every case, the measurement variables are specified as reflective indicators of the latent constructs in the model. 
The main differences between the original SCSB model and the ACSI model are the addition of a perceived quality component, as distinct from perceived value, and the addition of measures for customer expectations. (By deleting the perceived quality construct and its relationships from Fig. 2, the reader can readily see the original SCSB model specification in Fig.

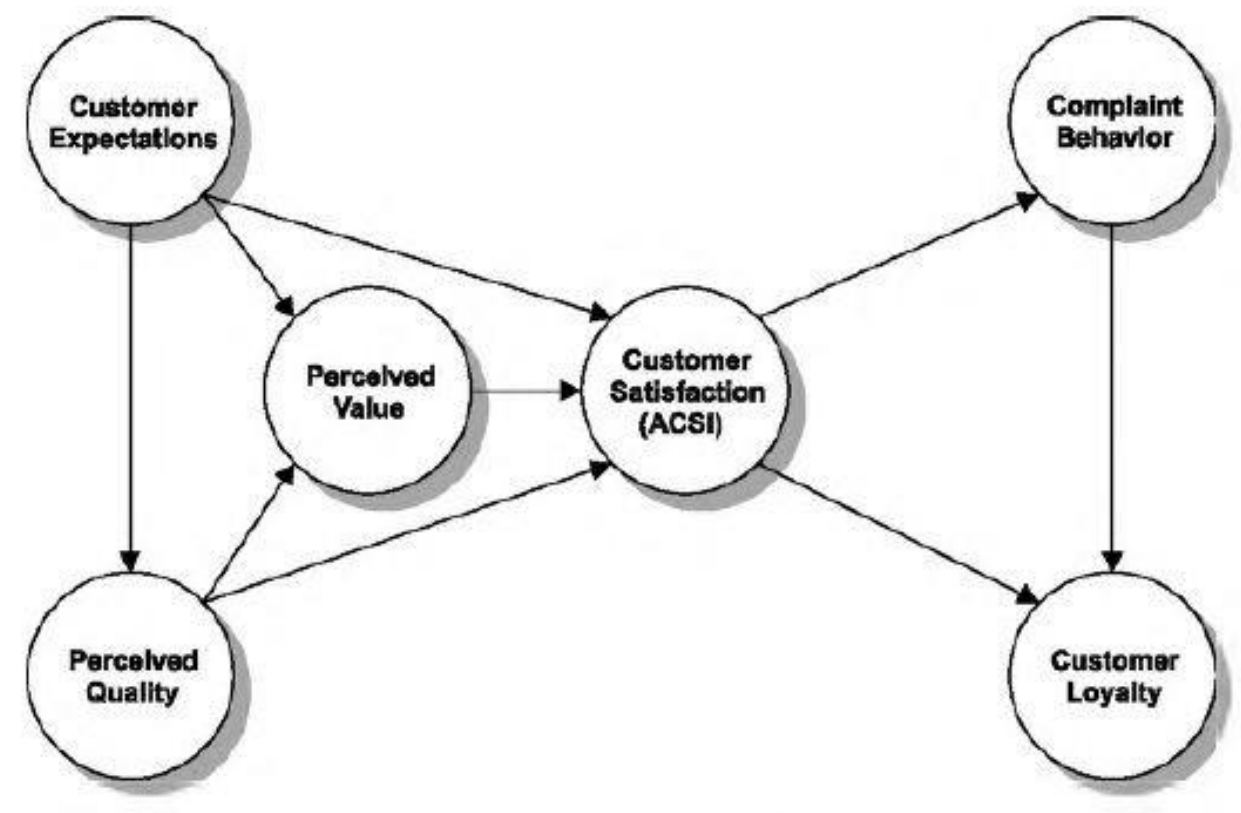

Fig. 2. The ACSI (American Customer Satisfaction Index) model.

\section{1.)}

Quality experts (Deming, 1981; Juran \& Gryna, 1988) delineate two primary components of the quality experience, the degree to which a product or service provides key customer requirements (customization) and how reliably these requirements are delivered (reliability). Asking customers to rate customization quality, reliability quality and overall quality allows the ACSI model to delineate a distinct quality construct that is separate from perceived value. In 1996, the ACSI survey and model were expanded to delineate two general types of perceived quality, product (physical good) quality and service quality. This change was made only for manufacturing durables as they contain both a large product and a large service component. The survey questions used in other sectors to measure perceived quality (customization, reliability, and overall quality) are asked separately for both the product and service aspects of the offering.

The perceived value construct is operationalized using the same two survey questions as in the original Swedish model, a rating of the price or prices paid for the quality received and a rating of the quality received for the price or prices paid. The ACSI model predicts that as both perceived value and perceived quality increase, customer satisfaction should increase. Expected customization and expected reliability were also added to the survey to measure customer expectations using three survey measures (overall expectations, expected customization and expected reliability). 
Fornell et al. (1996) argue that the inclusion of both perceived quality and perceived value into the ACSI model provides important diagnostic information. As the impact of value increases relative to quality, price is a more important determinant of satisfaction. As quality is a component of value, the model also links quality directly to value.

There are two measures of customer loyalty in the ACSI model. The first is a rating of repurchase likelihood. The second measure is constructed from two survey ratings: the degree to which a firm could raise its price(s) as a percentage before the customer would definitely not choose to buy from that firm again the next time (given the customer has indicated that he or she is likely to repurchase), and the degree to which a firm would have to lower its price(s) as a percentage before the customer would definitely choose again from that firm the next time (given the customer has indicated that he or she is unlikely to repurchase).

\subsection{The first NCSB model}

The first NCSB model was identical to the original American model with the exception that it included corporate image and its relationships to customer satisfaction and customer loyalty. Key to perceptions of corporate image is the organization-related associations held in a customer's memory. These associations are similar to schemas in cognitive psychology (Brands- ford \& Franks, 1971; Brandsford \& Johnson, 1972). According to Fishbein and Ajzen (1975), attitudes are functionally related to behavioral intentions, which predict behavior. As a type of attitude, corporate image should be updated as schemas, including customer satisfaction, are changed. Corporate image should, in turn, affect behavioral intentions such as loyalty. Selnes (1993) hypothesized and documented these effects for brand reputation (a large part of overall corporate image) in a study of four companies from different industries. Finally, in two studies related to the impact of corporate image on customer intent, Andreassen and Lindestad (1998a,b) found a positive correlation between the constructs.

In keeping with the evolution in marketing from a transactional to a relational orientation among service providers, the NCSB model was expanded over time to include a relationship commitment construct. The construct has evolved to focus on both the affective and calculative components of commitment. While the affective component is "hotter" or more emotional, the calculative component is based on "colder" aspects of the relationship such as switching costs. The commitment constructs are modeled as mediating the effects of satisfaction on loyalty (behavioral intentions).

\subsection{The ECSI model}

The ECSI represents another variation on the ACSI model (Eklof, 2000). The customer expectations, perceived quality, perceived value, customer satisfaction, and customer loyalty constructs are modeled the same as in the ACSI. The distinction between service quality and product quality in a subset of ACSI industries is standard in the ECSI. The measures of customer 
loyalty are also somewhat different. For the ECSI the loyalty measures include likelihood of retention, likelihood of recommending the company or brand, and whether the amount customers are likely to purchase will increase.

There are two more fundamental differences between the ACSI and ECSI models. First, the ECSI model does not include the incidence of complaint behavior as a consequence of satisfaction. As described subsequently, there is good reason for this change. Second, in keeping with the original NCSB, the ECSI model incorporates corporate image as a latent variable in the model. Corporate image is specified to have direct effects on customer expectations, satisfaction and loyalty.

\subsection{Model estimation}

The estimation of satisfaction indices and models such as the national index models must accommodate several constraints. The models involve a network of cause and effect relationships and must be estimated accordingly. They predict a pattern of relationships and effects within a nomological network (Bagozzi, 1980). The models also contain latent or unobservable psychological variables (such as perceived quality, satisfaction, image and loyalty). As described earlier, these variables are only measurable indirectly using multiple concrete proxies. Finally, it is essential to be able to operationalize performance on the latent variables (as through a weighted index of multiple survey measures) to provide benchmarks.

Partial least squares or PLS is a causal modeling method that is particularly well suited to these requirements (Gustafsson \& Johnson, 1997; Steenkamp \& van Trijp, 1996). The Swedish, American and European models are all estimated using this method. PLS is an iterative estimation procedure that integrates aspects of principal-components analysis with multiple regression (Wold, 1982). When estimating a model such as the ACSI (where all survey measures are reflective indicators of more latent variables), the procedure essentially extracts the first principal component from each subset of measures for the various latent variables and uses these principal components within a system of regression models. The algorithm then adjusts the principal-component weights to maximize the predictive power of the model.

Unlike covariance structure analysis (Joreskog, 1970), which focuses on explaining covariance, the objective of PLS is to explain variance. Because PLS is conceptually similar to principal components, the latent variables (LVs) are easily operationalized as weighted indices of their measurement variables (MVs). In contrast, covariance structure analysis is based on true score theory; the emphasis is on understanding covariances or relationships among unobservable variables. PLS is also well suited to small samples and the skewed distributions that are common in satisfaction research (for a detailed discussion of PLS see Fornell \& Cha, 1994).

\subsection{Model tests}


Although tests of competing or alternative approaches are relatively common in transaction-specific research $(\mathrm{Yi}, 1991)$, there has been little in the way of model tests for cumulative satisfaction. Modeling cumulative satisfaction involves a balancing of two goals. One is to provide a descriptive understanding of the relationships surrounding satisfaction. The other is to be able to predict key business performance benchmarks, particularly satisfaction and loyalty.

To provide support for the current ACSI model specification, Fornell et al. (1996) estimated the model across customers within each of the seven sectors of the US economy included in the survey (manufacturing/non- durables, manufacturing/durables, transportation/communication/utilities, retail, finance/insurance, other services and public administration/government). Of the eight predicted relationships for each of the seven sectors (56 total predicted relationships), 54 of the 56 or $96 \%$ of the relationships were significant in the predicted direction. The ACSI model results also support the satisfaction index itself. The standardized loadings for the three satisfaction measures (expectancy disconfirmation, comparison to ideal, and overall satisfaction) averaged $0.883,0.847$ and 0.910 , respectively, across the sectorlevel models. Moreover, the loadings are all significantly higher than the path coefficients involving satisfaction and other constructs in the model. This supports the construct and discriminant validity of the resulting index.

Johnson, Nader, and Fornell (1995) explicitly test alternative model specifications of the relationships among expectations, perceived performance (value), and customer satisfaction using the Swedish data. These authors argue that, for a complex and infrequently purchased service (bank loans), strong expectations fail to exist before the service is consumed. Rather, measured expectations are an artifact of the service delivery process. The authors propose and estimate an alternative "expectations-artifact" model. Accordingly, although expectations co-vary with performance and performance has a direct effect on satisfaction, expectations have no direct effect on satisfaction. They compare this model to alternatives including the original SCSB specification (performance affects satisfaction, expectations affect both performance and satisfaction).

The models were tested separately using firm-level SCSB data for commercial banks, other services as a group, and products as a group. Whereas the results support the original SCSB specification as superior for the majority of firms in the study (other services and products), the expectations- artifact model proved superior for commercial banks. The models tested did not, however, include the perceived quality construct now incorporated into the national index models or the consequences of satisfaction.

\section{Critique and proposed improvements}

The focus of our critique is more on the satisfaction model specifications currently being used rather than the model constructs. Constructs such as satisfaction and loyalty endure. At the same time, there is no reason to believe that the same model will accurately describe these constructs at different points in time (Simon, 1978). As times change, conditions and knowledge 
evolve, and national satisfaction index models must adapt to the changes. We focus primarily on the ACSI model specification in Fig. 2, but include the other models as well.

\subsection{Strengths and weaknesses}

The ACSI model has several strengths. As reported earlier, the three measures of cumulative satisfaction (overall satisfaction, expectancy dis- confirmation, and comparison to an ideal) provide a reliable satisfaction index. The estimation method used to estimate the model and operationalize the index (PLS) is also well suited to the research context. As a result, the model provides valuable benchmarks for satisfaction and related constructs such as quality, value, and loyalty. The ACSI and SCSB indices are also systematically and predictably related to financial and accounting returns (see Edvardsson, Johnson, Gustafsson, \& Strandvik, 2000) and productivity levels (Huff, Fornell, \& Anderson, 1996; Anderson, Fornell, \& Rust, 1997).

Weaknesses in the ACSI and other national models relate primarily to their model specification. Some relationships involving the antecedents and consequences of satisfaction in the ACSI are conceptually and/or empirically weak. Consider first the path from expectations to value. A review of the expectations measures used in the ACSI (see Fornell et al., 1996) reveals that they all pertain specifically to quality rather than value. Hence, the logic behind the expectations to value linkage is unclear. Fornell et al. (1996) report that this effect is nonsignificant in one of the seven industry sectors tested (public administration/government) and quite small in two other sectors (manufacturing durables and other services), even though very large sample sizes were used. This suggests that the link from expectations to value may be removed. Further, one could argue that through cumulative experience with the service provider the customer's expectations become more rational or precise (Rust, Inman, Jia, \& Zahorik, 1999), leading to confirmation rather that disconfirmation of expectations. Expectations either become passive or they cease to exist in these situations (Oliver, 1997). This is again an argument for eliminating expectations as a construct when using cumulative satisfaction measures.

There are also reasons to question the link from expectations to satisfaction. Johnson et al. (1995) demonstrate that there may be no direct effect of customer expectations on customer satisfaction using SCSB data. Rather, expectations can be an artifact of service delivery or product consumption in some situations (where customers have little experience and weak expectations). Similarly, Fornell et al. (1996) report a non-significant effect of expectations on satisfaction for the entire finance/insurance industry sector using ACSI data. In two other service industry sectors (transportation, communications and utilities, and other services), the effect is sufficiently small as to question whether an expectations to satisfaction link is warranted. Even in industries where customers have significant consumption experience, our review of several firm-level ACSI models (as for utility services, automobiles, and food and beverage products) reveals that small or nonsignificant impacts of expectations on satisfaction are common. This is likely due to the strong link between the expectations and quality constructs in the ACSI survey questions. Arguably, quality completely mediates the impact of quality expectations on satisfaction, which would 
eliminate the need for a separate expectations construct. As a result, expectations are removed from the new nCsb model.

The link from quality to value in all the current models is particularly problematic. Certainly, adding a link from quality to value adds to the predictive value of the model. This is straightforward, as quality is a major part of the value equation. It is difficult, however, to interpret this path. To be a pure antecedent in a cause and effect model, there must be some hypothesis or rationale regarding the mechanism by which one construct influences or produces a change in another (Bagozzi, 1994). In the current models, the relationship from quality to value may be tautological as well as causal because quality is related to value by definition.

The problem occurs when assigning meaning to the path coefficients involving value visa-vis quality, and particularly, the direct path from quality to value. It is impossible to know how much of the impact that quality has on value is due to cause and effect, and how much is true by definition. Even the causal part of the path is questionable. Later we propose to remove the tautology by replacing the value construct with a perceived price construct. But what, then, is the nature of a causal effect of perceived quality on perceived price? If anything, market research would suggest that price is a cue to quality, not the opposite (Gerstner, 1985; Monroe, 1973).

Another possible limitation of the current model specifications is that all of the effects of quality, value, and expectations on loyalty are mediated by satisfaction. Cumulative satisfaction models, such as the ACSI, rest heavily on multidimensional expectancy-value model formulations (Bagozzi, 1992). Accordingly, customers have distinguishable psychological responses to their consumption experience (quality and value). These are the primary antecedents of customers' attitudes or stated evaluations regarding their consumption experience (cumulative customer satisfaction). This satisfaction, in turn, influences customers' behavioral intentions in the form of a predisposition to repurchase and consume the product or service again (customer loyalty).

It is common in expectancy-value models to view attitude and behavioral intention constructs as only partially mediating the effects of an individual's belief structure on outcomes (Bagozzi \& Yi, 1994). The degree of mediation depends on the strength of the overall evaluation. Thus, quality and/or value may have some direct effect on loyalty that is not mediated by satisfaction. This is consistent with Bloemer and Kasper (1995) who argue and show that more explicit or strongly held satisfaction evaluations have a greater effect on customer loyalty than do more implicit or weakly held evaluations. The partial mediation argument is also consistent with the notion that customers do not necessarily recall an existing evaluation when responding to an intentions-related question (as when assessing loyalty). At least in part, they construct a response after the question is asked (Feldman \& Lynch, 1988; Simmons, Bickart, \& Lynch, 1993). Finally, the argument is consistent with the notion that customers reweigh price information when evaluating loyalty vis-a-vis satisfaction (Mittal, Ross, \& Baldasare, 1998).

Turning attention to the consequences of satisfaction, it is important to realize that Hirschman's (1970) exit-voice theory, on which the consequences of satisfaction in the ACSI model are based, was developed in a time when formal complaint management systems were either non-existent or relatively primitive. There was little focus on complaint handling as a mechanism 
for retaining customers and increasing profitability. Theoretically, complaining was a natural consequence of low satisfaction, not an opportunity to increase satisfaction. Over the last decade, however, researchers have realized the importance and power of these mechanisms toward increasing satisfaction (Heskett, Sasser, \& Hart, 1990). As a result, complaint resolution has become more important than complaints per se. Researchers now emphasize the potential for complaint management and service recovery systems to increase satisfaction (Smith, Bolton, \& Wagner, 1999). Therefore, just how complaints are handled and resolved should be a driver rather than a consequence of satisfaction.

There is also a methodological reason to view complaints or complaint handling as a driver of satisfaction. Because the complaints and recovery activity necessarily occur prior to the customer being surveyed, it is problematic to view them as anything other than antecedents to overall satisfaction. This suggests that measures for complaint handling and resolution be added to national satisfaction surveys.

Another option is to propose reciprocal causation, or a non-recursive relationship, between satisfaction and complaint behavior. Accordingly, complaint behavior should reduce cumulative satisfaction as an overall measure of the customer's experience while satisfaction, in turn, reduces complaint behavior in accord with Hirschman's theory. However, positing reciprocal causation has its own problems. Temporal priority of cause to effect is a necessary part of causal explanations in the philosophy of science literature (Bagozzi, 1994). In a cross-sectional survey such as the ACSI, it is impossible for two constructs to be causes of each other and satisfy the constraint of temporal priority. Thus, a reciprocal relationship appears unwarranted.

Now consider the addition of corporate image as a driver of expectations and satisfaction as in the NCSB and ECSI models. Corporate image has been modeled as a psychological anchor that affects perceptions of quality performance as well as satisfaction and loyalty (Andreassen $\&$ Lindestad, 1998a). But in the national index surveys, satisfaction and corporate image measures are collected simultaneously. As a result, customers' purchase and consumption experiences, summarized in their satisfaction evaluation, naturally influence their evaluations of corporate image. As argued below, it makes more sense to model satisfaction's contribution to corporate image.

\subsection{A new model}


Based on our discussion and review of the existing models, we propose a new model that addresses these limitations and concerns through a series of modifications and additions. The new model: (1) replaces the value construct with a "pure" price construct; (2) replaces customer expectations with corporate image as a consequence of satisfaction; (3) includes two aspects of relationship commitment as well as corporate image as drivers of loyalty; (4) incorporates the

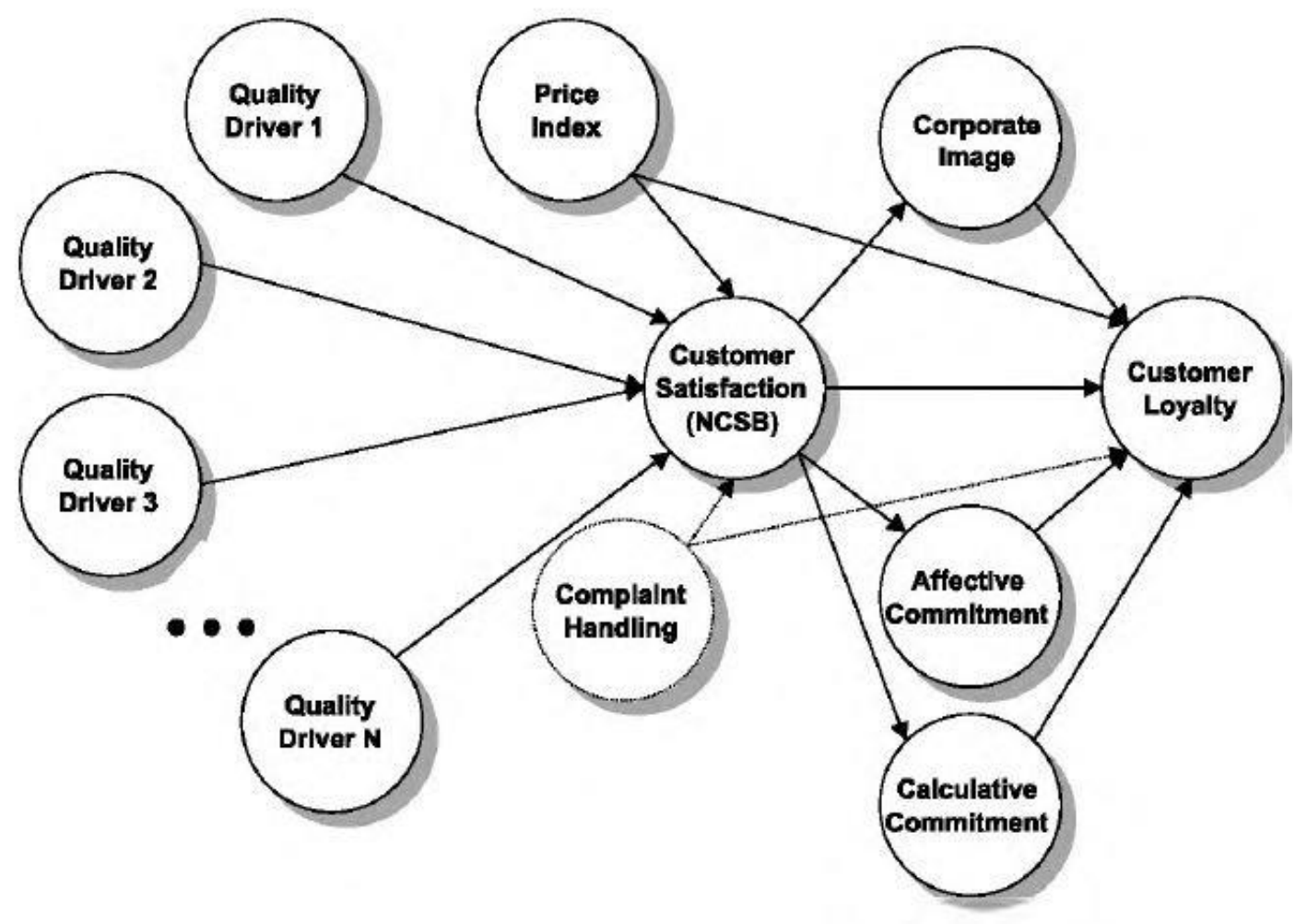

Fig. 3. The proposed model.

potential for direct effects of price on loyalty, and (5) includes complaint handling as a driver of both satisfaction and loyalty. These changes are part of our proposed model that is illustrated in Fig. 3.

The first recommended change is to replace the customer expectations construct in previous models with a corporate image construct. The crosssectional nature of national customer satisfaction data means that pre-purchase expectations are collected post purchase, or at the same time that satisfaction is measured. What is really being collected is a customer's perception of the company's or brand's corporate image. Moreover, this corporate image will have been affected by the customer's more recent consumption experiences, or customer satisfaction. Thus, corporate image should be modeled as an outcome rather than a driver of satisfaction. The effect of satisfaction on corporate image reflects both the degree to which customers' purchase and consumption experiences enhance a product's or service provider's corporate image and the consistency of customers' experiences over time.

The second recommended change is to replace complaint behavior with complaint handling, or how well any given complaint has been resolved. Complaint handling should have a 
direct effect on satisfaction as well as loyalty. Well-handled complaints should have a more positive effect on satisfaction while poorly handled complaints should have a more negative effect. As argued previously, this change reflects the more mature nature of complaint management systems and the fact that the complaint behavior and resolution occurs prior to the satisfaction evaluation. As the problem and its handling may also be salient when repurchasing the product or service or recommending it to others, complaint handling may also have a direct effect on loyalty. In Fig. 3, the complaint handling construct and its relationships are shown using dotted lines to signify that they only apply to those subset of customers who complained and could subsequently evaluate the complaint handling questions.

A third recommended change is to eliminate the tautology between perceived quality and perceived value. Adding the perceived quality construct to the ACSI model certainly provides more diagnostic information than was available under the original SCSB model. But because quality is part of value, the relationship is confounded. We recommend replacing the perceived value construct with a perceived price construct. We use survey questions that have customers evaluate price relative to a variety of benchmarks, including comparisons of the product's price versus expected price, competitors' prices, and quality. Extracting an index of what these survey measures have in common should measure a more "pure" price construct.

Our fourth recommendation is to better understand and predict customer loyalty as a key performance benchmark. As shown in Fig. 3, and consistent with earlier models, satisfaction still has a direct effect on loyalty. This reflects the degree to which customers' purchase and consumption experiences directly affect loyalty. But corporate image should also directly affect customer loyalty. The corporate image effect captures such things as the ongoing inclusion of certain brands in a customer's set of considered brands (consideration set) over time and more long term or memory-based evaluations of the brand (Johnson \& Gustafsson, 2000).

In keeping with the emerging view of marketing as more than just exchange (see for example Berry, 1983; Gronroos, 1990), we propose using two relationship commitment constructs from the NCSB to help explain more variation in loyalty. Relationship commitment picks up on those dimensions that keep a customer loyalty to a product or company even when satisfaction and/or corporate image may be low. We distinguish between the affective and calculative bases of commitment. Recall that the affective component is "hotter" or more emotional. It captures the affective strength of the relationship that customers have with a brand or company and the level of involvement and trust that results. This affective commitment serves as a psychological barrier to switching. The calculative component is based on "colder" or more rational and economical aspects such as switching costs. This includes the degree to which customers are held hostage to a particular service company or location. The commitment constructs are modeled as mediating the effects of satisfaction on loyalty.

Finally, we recommend that direct effects of price and/or quality on loyalty be considered. The model in Fig. 3 breaks quality up into different quality dimensions that make up the "lens" of the customer (Johnson \& Gustafsson, 2000). We view it as a matter of choice as to whether one uses an overall quality index (as in the ACSI), distinguishes between product and service quality 
(as in the ECSI), or uses quality dimensions that are more tailored to the industry or category type (which is the case in the NCSB). This decision should depend on the level of detail and diagnostic information desired. Our point is that, because satisfaction is an attitude-type evaluation, the degree to which satisfaction will completely mediate the effects of price and quality dimensions on loyalty will be a function of the strength of the satisfaction evaluations. In those cases where satisfaction evaluations are weaker, or customers have less confidence in their evaluations, price and/or quality may have more direct effects on loyalty. We incorporate the direct effect of price on loyalty in Fig. 3 to illustrate this possibility. This is because price is particularly likely to receive increased attention in customers' repurchase (versus satisfaction) evaluations (Mittal et al., 1998).

\section{Empirical study}

The proposed changes have been incorporated into the new NCSB model. In keeping with the SCSB and the ACSI, the NCSB is estimated using telephone surveys from a national probability sample of 6900 customers. For the companies included in the study, interviews were conducted with 200 of their existing customers. To be eligible for interview, a prospective respondent must qualify as the purchaser of specific services within defined time-periods. Thus, the definition of "customer" in the NCSB is "[A]n individual chosen randomly from a large universe of potential buyers who qualify by recent experience as the purchaser or consumer of one service of one specific company which supplies household consumers in Norway'.

Drawing from this sample, the new NCSB-model was tested using 2755 respondent interviews from five different industries (airline, banks, bus transportation, service stations and train transportation). The survey was conducted using a professional marketing research bureau. Each interview lasted approximately 15 minutes.

Measures. As can be seen in Table 1, all constructs are measured using multiple indicators. The customer satisfaction or NSCB questions are identical to those used in the original Swedish and American models. Price is operationalized using various price benchmarks (Mayhew \& Winer, 1992; Winer, 1986), while corporate image is measured using questions pertaining to overall image and other image benchmarks and is similar to reputation (see Johnson \& Gustafsson, 2000). The affective commitment and calculative commitment measures are adapted from the works of Samuelsen (1997), Samuelsen and Sandvik (1997), Kumar, Hibbard, and Stern (1994) and Meyer and Allen (1984). The behavioral intention measures for operationalizing loyalty are based on Zeithaml, Parasuraman, and Berry (1996). 
The NCSB quality drivers are partly based on focus group interviews with customers and managers from the different industries and partly based on the SERVQUAL instrument developed by Parasuraman, Zeithaml, and Berry (1988) and Zeithaml, Parasuraman, and Berry (1990).

Table 1

Measurement variables for price, satisfaction, corporate image, commitment and loyalty

\begin{tabular}{ll}
\hline Measurement variable & Latent variable \\
\hline 1. Overall satisfaction & $\begin{array}{l}\text { Customer satisfaction } \\
\text { Customer satisfaction }\end{array}$ \\
2. Performance versus the customer's ideal service provider & \\
in the category & Customer satisfaction \\
3. Expectancy disconfirmation (performance that falls short & \\
of or exceeds expectations) & Price \\
4. Price compared to quality & Price \\
5. Price compared to other companies & Price \\
6. Price compared to expectations & Corporate image \\
7. Corporate image compared to other companies & Corporate image \\
8. Image of the store (branch) you deal with & Corporate image \\
9. What friends say about the corporate image & Corporate image \\
10. Overall corporate image & Complaint behavior \\
11. The compensation offered by the company & Complaint behavior \\
12. Employees treated you politely and with respect when you & \\
complained & Affective commitment \\
13. The pleasure taken in being a customer of the company & Affective commitment \\
14. Identification with what the company stands for & Affective commitment \\
15. Presence of reciprocity in the relationship & Affective commitment \\
16. Feeling of belongingness to the company & Calculative commitment \\
17. The economics (benefits versus costs) of the alternative & Calculative commitment \\
18. Economic suffering if the relationship is broken & Calculative commitment \\
19. Location advantages versus other companies & Loyalty \\
20. Likelihood of retention & Loyalty \\
21. Likelihood of speaking favorably about the company to others & Loyalty \\
22. Likelihood of recommending the company to others &
\end{tabular}

Merging these efforts led to a five-factor solution, consisting of tangibles, reliability, responsiveness, assurance and empathy. As can be seen from Table 2, all five constructs are measured using multiple indicators. Only minor industry adjustments were allowed, as cross company comparison is one of the major goals of the NCSB. A 10-point Likert-type scale was applied to measure the different constructs. The questionnaire consisted of three different scale types anchored from bad to good, low to high degree, and unlikely to likely depending on the question. In addition, respondents were offered a "do not know" and a "will not tell" category in case of lacking knowledge, indifference or unwillingness to answer. These categories were recoded as missing and the average number of missing values by industry were $8 \%$ for airlines, $9 \%$ for trains, $9 \%$ for gas stations, $10 \%$ for banks, and $12 \%$ for buses. The missing values were replaced with series means (Downey \& King, 1998) to estimate the model for each industry.

\subsection{Model results}

The proposed model was estimated using PLS (following Fornell, 1992; Fornell et al., 1996) across individual respondents for each of five industries in our overall sample: (1) banking 
$(\mathrm{n}=902),(2)$ gas stations $(\mathrm{n}=500),(3)$ airlines $(\mathrm{n}=400),(4)$ bus transportation $(\mathrm{n}=203)$ and (5) train transportation $(n=750)$. We first discuss the quality of the measurement model and then examine the latent variable model results.

The measurement variable (MV) loadings for each of the five models are all relatively large and positive. The loadings should exceed 0.707 to ensure that at least half of the variance in the observed variable is shared with the construct (the squared correlation equals the variance explained, where $0.7072=50 \%$ ). In PLS estimation, this criterion is referred to as communality

Table 2

SERVQUAL measurement variables

\begin{tabular}{ll}
\hline Measurement variable & Latent variable \\
\hline 1. Equipment and facilities & Tangibles \\
2. Accessibility & Tangibles \\
3. Comfort & Tangibles \\
4. Employees conduct and behavior & Tangibles \\
5. Opening hours & Tangibles \\
5a. Buildings fit in the surroundings & Tangibles \\
5b. Product selection & Tangibles \\
6. Deliver service at the right time & Reliability \\
7. Deliver service of the right quality & Reliability \\
8. Helping when problems occur & Reliability \\
9. Information about delays in service & Responsiveness \\
10. Ability to provide prompt service & Responsiveness \\
11. Assigning time to help customers & Responsiveness \\
12. Information about the services & Assurance \\
13. Trust in company & Assurance \\
14. Employees create security & Assurance \\
15. Employees treat you with respect & Assurance \\
16. Employees are polite & Assurance \\
17. Employecs give personal attention & Empathy \\
18. Employes understand your nceds & Empathy \\
19. Employees treatment of you & Empathy \\
\hline
\end{tabular}

a Not in the banking and gas station industries.

${ }^{\mathrm{b}}$ Only in the gas station industry.

${ }^{\circ}$ Not in the gas station industry.

(Fornell \& Cha, 1994). Table 3 reports the average communality for each latent variable in each industry. Average communality is greater than 0.5 in 51 of 55 cases (92\%). The four exceptions are all for the tangibles construct from the SERVQUAL drivers, implying that this construct contains more than one component or latent variable. Communality exceeded the 0.5 criterion for all of the non-SERVQUAL constructs. 
Another criterion used to evaluate the validity of the measurement model, specifically the discriminant validity of the model, is to explore whether each LV or construct shares more variance with its MVs (indicators) than it does with other constructs in the model. This is examined by looking at the percentage of MV loadings that exceed the LV correlations. The percentage is quite low, equaling $7 \%, 1 \%, 6 \%, 4 \%$ and $4 \%$ for the airline, bank, bus, gas station, and train models, respectively. It is important to note that most of the violations occur for the SERVQUAL constructs. There are 86 out of a total of 1910 comparisons (across the five models) where an LV correlation exceeds an MV loading for the two constructs involved. Of these 86 cases, 57 (66\%)

Table 3

Average communality by latent variable and industry

\begin{tabular}{|c|c|c|c|c|c|c|}
\hline Average communality & Airlines & Banks & Buses & \multicolumn{2}{|c|}{ Gas stations } & Trains \\
\hline Tangibles & 0.423 & 0.545 & 0.492 & \multicolumn{2}{|c|}{0.416} & 0.444 \\
\hline Reliability & 0.631 & $0.74 \hat{3}$ & 0.669 & \multicolumn{2}{|c|}{0.699} & 0.539 \\
\hline Responsiveness & 0.728 & 0.705 & 0.663 & \multicolumn{2}{|c|}{0.853} & 0.675 \\
\hline Assurance & 0.619 & $0.66 \hat{3}$ & 0.648 & \multicolumn{2}{|c|}{0.602} & 0.635 \\
\hline Empathy & 0.783 & 0.786 & 0.810 & \multicolumn{2}{|c|}{0.752} & 0.745 \\
\hline Price & 0.667 & 0.697 & 0.671 & \multicolumn{2}{|c|}{0.601} & 0.726 \\
\hline Satisfaction & 0.708 & 0.735 & 0.685 & \multicolumn{2}{|c|}{0.703} & 0.764 \\
\hline Corporate image & 0.632 & 0.626 & 0.653 & \multicolumn{2}{|c|}{0.636} & 0.609 \\
\hline Affective commitment & 0.683 & 0.733 & 0.584 & \multicolumn{2}{|c|}{0.678} & 0.650 \\
\hline Calculative commitment & 0.585 & 0.521 & 0.548 & \multicolumn{2}{|c|}{0.520} & 0.571 \\
\hline Loyalty & 0.816 & 0.820 & 0.777 & \multicolumn{2}{|c|}{0.770} & 0.777 \\
\hline \multicolumn{2}{|l|}{ 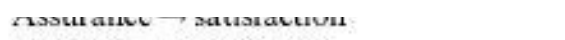 } & v.1.0u & v.ues & $u .0>1$ & vidur & v.ved \\
\hline \multicolumn{2}{|l|}{ Empathy $\rightarrow$ satisfaction } & $0.094^{2}$ & $0.034^{2}$ & 0.023 & $0.045^{2}$ & $0.060^{\mathrm{a}}$ \\
\hline \multicolumn{2}{|c|}{ Price $\rightarrow$ satisfaction } & 0.126 & 0.295 & $0.142^{8}$ & 0.196 & 0.159 \\
\hline \multicolumn{2}{|c|}{ Satisfaction $\rightarrow$ corporate image } & 0.531 & 0.575 & 0.545 & 0.491 & 0.433 \\
\hline \multicolumn{2}{|c|}{ Satisfaction $\rightarrow$ affective commitment } & 0.524 & 0.652 & 0.445 & $0.493^{2}$ & 0.473 \\
\hline \multicolumn{2}{|c|}{ Satisfaction $\rightarrow$ calculative commitment } & 0.155 & 0.265 & 0.263 & 0.243 & 0.272 \\
\hline \multicolumn{2}{|c|}{ Satisfaction $\rightarrow$ loyalty } & 0.207 & 0.289 & 0.210 & 0.274 & 0.130 \\
\hline \multicolumn{2}{|l|}{ Price $\rightarrow$ loyalty } & 0.096 & 0.098 & $0.076^{\circ}$ & $0.072^{i}$ & $0.062^{\mathrm{a}}$ \\
\hline \multicolumn{2}{|c|}{ Corporate image $\rightarrow$ loyalty } & 0.256 & 0.172 & 0.251 & 0.160 & 0.236 \\
\hline \multicolumn{2}{|c|}{ Affective commitment $\rightarrow$ loyalty } & 0.374 & 0.345 & $0.166^{\mathrm{2}}$ & 0.361 & 0.348 \\
\hline \multicolumn{2}{|c|}{ Calculative commitment $\rightarrow$ loyalty } & 0.077 & $0.052^{a}$ & $0.191^{8}$ & 0.107 & 0.213 \\
\hline
\end{tabular}

${ }^{a}$ Adjusted $t$-statistic insignificant $(p>0.05)$.

involved tangibles, which is consistent with the communality results, and 20 (23\%) involved assurance. We conclude that both the convergent and discriminant validity in the models is strong. What weaknesses exist are concentrated in the SERVQUAL part of the model. To evaluate the latent variable results, we first examine the size and significance of the predicted path coefficients. We then examine the ability of the model to explain variation in the endogenous variables, especially satisfaction and loyalty. Table 4 reports the size and significance of each path for each industry. Following Fornell et al. (1996), Jackknife estimates were generated to evaluate the significance of the paths. As the majority of path coefficients are significant, only those paths that are not significant $(\mathrm{p}>0.05)$ are marked in the table. Out of 70 possible paths (14 paths for each of five industry models), 48 (68.5\%) are significant in the predicted direction. 
Again, however, it is important to evaluate the SERVQUAL-related paths separately from the other NCSB path coefficients. Most of the insignificant paths involve the SERVQUAL constructs. Whereas only 11 of 25 SERVQUAL-related paths are significant (44\%), 37 of 45 of the non-SERVQUAL paths are significant (82\%). Among the eight non-significant paths involving the non-SERVQUAL constructs, three are for the direct effect of price on loyalty, which we do not expect to be significant in every case. Recall that such direct effects of satisfaction drivers on loyalty are only likely when the satisfaction evaluation or attitude is relatively weak. In two cases (banks and buses), calculative commitment had no direct effect on loyalty. There is only one path that is not in the right direction, which is a negative but non-significant effect of the responsiveness construct (from SERVQUAL) on satisfaction for trains.

The second indicator of the model's performance is its ability to explain the important latent variables in the model, especially customer satisfaction and loyalty. We pay particular attention to explained variation in loyalty given the addition of the corporate image and relationship commitment constructs. The variance explained in the endogenous variables by industry is reported in Table 5. An important finding is that, in four out of five industries, the model explains more variation in loyalty than in satisfaction. Moreover, in four of five industries the model explains more than $50 \%$ of the variation in loyalty evaluations. The R2 measures for overall customer satisfaction range from 0.49 for the gas stations to 0.56 for bus transportation (average R2 of 0.54). The R2 measures for customer loyalty range from 0.46 for bus transportation to 0.63 for the airline industry (average R2 of 0.57 ). Contrast this with the ACSI model (Fornell et

Table 5

Variance explained in the latent variables by industry

\begin{tabular}{llllll}
\hline Variance explained $\left(R^{2}\right)$ & Airlines & Banks & Buses & Gas stations & Trains \\
\hline Satisfaction & 0.530 & 0.564 & 0.564 & 0.491 & 0.531 \\
Corporate image & 0.282 & 0.330 & 0.300 & 0.241 & 0.188 \\
Affective commitment & 0.275 & 0.425 & 0.199 & 0.244 & 0.224 \\
Calculative commitment & 0.024 & 0.071 & 0.069 & 0.059 & 0.074 \\
Loyalty & 0.625 & 0.622 & 0.463 & 0.563 & 0.587 \\
\hline
\end{tabular}

al., 1996), which explains more variation in satisfaction than in loyalty and where the average variation in loyalty explained is only 0.36 or $36 \%$. The variances explained for the other endogenous constructs (corporate image, affective commitment, and calculative commitment) are generally lower. But in each case, the constructs only have a single antecedent in the model (customer satisfaction).

\subsection{Results for complaining customers}

Separate models were run for those customers who complained either formally or informally to the company or service provider and, therefore, answered the complaint handling questions in the survey. The models include the complaint-handling construct (see Fig. 2) that is measured using two indicators (quality of the compensation offered by the company, and the 
degree to which employees treated customers politely and with respect when they complained; see Table 1). For bus transportation and airlines, the sample of complaining customers was quite small ( $\mathrm{n}=14$ and 20, respectively). We thus focus on the models for train transportation $(\mathrm{n}=154)$, banking $(n=211)$ and gas stations $(n=49)$, where Jackknife estimates are again used to evaluate the significance of the effects. The MV loadings for the complaint-handling construct were large and positive in each case and exceeded any LV correlation involving the construct.

Complaint handling has little effect in the models. The path coefficient for the effect of complaint handling on satisfaction equals $-0.078,0.058$ and -0.095 for trains, banks and gas stations, respectively, none of which are significant. The path coefficients for the direct effect of complaint handling on loyalty equal $0.026,0.122$ and 0.128 for trains, banks and gas stations, respectively. The only significant direct effect of complaint handling on loyalty is the positive effect for banks. Thus, while the model was successful at isolating a complaint-handling construct, the construct did not have much effect on either satisfaction or loyalty. We discuss the likely reason for this in the next section.

\section{Summary and discussion}

A number of both national and international customer satisfaction barometers or indices have been introduced in the last decade, most of which are embedded within a system of cause and effect relationships (satisfaction models). Of critical importance to the validity and reliability of such indices is that the models and methods used to measure customer satisfaction and related constructs continue to learn, adapt, and improve over time. Building on recent findings and current research trends, we propose and test a number of modifications and improvements to the national index models that are now part of the Norwegian Customer Satisfaction Barometer (NCSB) model. We find general support for the proposed modifications using data from the NCSB survey.

We summarize and discuss our findings with respect to each of the proposed changes. One change was to add multiple benchmark comparisons for price to isolate a perceived price index. The model successfully isolates perceived price, and by removing "value" from the model and replacing it with price, we remove the overlap that exists between value and quality in, for example, the ACSI and ECSI models. We also argued that price may have a direct effect on loyalty over and above its indirect effect via satisfaction. This is because satisfaction, as an attitude-type construct, may only partially mediate the effect of quality and price on loyalty. The direct effect of price attractiveness on satisfaction was positive and significant in four of five industries, bus transportation being the exception. The path coefficients range from 0.13 for airlines to 0.30 for banks. The direct effect of price on loyalty is significant in two of the five industries, airlines and banks (path coefficients of 0.096 and 0.098, respectively). These results are consistent with the prediction that, in some industries, customers reweigh the importance of price when moving from satisfaction to loyalty evaluations. It is not surprising that the direct effect of price on loyalty is greatest in two price-competitive industries, airlines and banks. 
Building upon the original NCSB model, our proposed model also includes two relationship commitment variables. Affective commitment captures more of the positive (or negative) relationship and trust that has built up between company and customer over time. Calculative commitment captures more of the economic consequences or costs associated with switching product or service providers. Both constructs are positively affected by satisfaction in four of five industries. As for the effect of price on satisfaction, the exception is the bus transportation industry. Satisfaction has a larger effect on affective commitment (ranging from 0.493 for gas stations to 0.652 for banks) than on calculative commitment (ranging from 0.155 for airlines to 0.272 for train transportation). This is not surprising. Satisfaction should be a major contributor to the strength of relationship and resulting customer trust (Hart \& Johnson, 1999). In contrast, while satisfaction should influence the economics of switching, customers may be held economically hostage to particular service providers or locations even when satisfaction is low (Jones \& Sasser, 1995).

One of the most important findings is the large positive effect that affective commitment has on loyalty. The effect is significant in four of five categories, bus transport again being the exception. In these four industries, affective commitment has a larger effect on loyalty than does satisfaction directly. This suggests that satisfaction affects loyalty largely through its ability to build strong relationships between companies and customers. Adding the commitment variables has the benefit of greatly increasing the model's ability to explain variation in loyalty vis-a-vis the other national index models.

Another major change is that we replace customer expectations, as an antecedent to satisfaction, with corporate image as a consequence of satisfaction. Recall that this change is based on the cross-sectional nature of the national index data, where a customer's consumption experiences (satisfaction) should have some influence on their perceptions of corporate image. The model is successful at isolating the corporate image construct, and the construct behaves as expected. Satisfaction has a consistently large effect on corporate image in each industry (ranging from 0.433 for trains to 0.575 for banks). This reflects the contribution that consumption experiences have on corporate image as well as the consistency between a customer's experiences and corporate image over time. The effect of corporate image on loyalty is smaller but significant in each of the five industries (ranging from 0.160 for gas stations to 0.256 for airlines). We believe that this captures the ongoing inclusion of brands or companies with strong corporate images among those that customers ultimately consider for purchase (i.e., the consideration set).

The direct effect of satisfaction on loyalty, which ranges from a low of 0.130 for trains to a high of 0.289 for banks, is also positive and significant for each industry. This direct effect captures the effects of satisfaction on loyalty that are not mediated by the corporate image or commitment constructs. Given that we have added more drivers of loyalty, it is useful to examine the total effect that satisfaction has on loyalty in each case. The total effect is the sum of all direct and indirect effects linking satisfaction and loyalty, which equals $0.551,0.627,0.471,0.557$ and 0.458 respectively, for airlines, banks, buses, gas stations and trains. As one would expect, the 
total effect of satisfaction on loyalty is greatest in those industries where Norwegian customers have greater choice among competitors, most notably banks, gas stations and airlines.

Complaint handling and the SERVQUAL constructs were two areas where the model did not perform as well as expected. In the ACSI model, complaint behavior is modeled as a consequence of satisfaction. Because complaint handing is an increasingly important means of improving satisfaction, we used the quality of complaint handling among complaining customers as a driver of both satisfaction and loyalty. Although we successfully isolate a complaint-handling construct, it has little effect on either satisfaction or loyalty. The most likely explanation is that complaint management systems in the industries are not particularly effective at creating satisfaction or loyalty. This is consistent with Fornell et al.'s (1996) analysis of ACSI data, which suggests that complaint management systems are only capable of neutralizing complaints. The finding is also consistent with Bolton (1999), who finds that service recovery is generally ineffective for a majority of customers in both a restaurant and hotel setting.

The NCSB model uses a variation on the SERVQUAL constructs (tangibles, reliability, responsiveness, assurance and empathy) as service quality dimensions across industries. In contrast, the ACSI uses an overall quality construct, while the ECSI distinguishes between overall service and overall product quality. As argued earlier, this is largely a matter of choice. How one specifies product or service quality depends on the level of detail versus generality desired in the research. Using the SERVQUAL dimensions is a natural place to start given that the NCSB focuses on service industries. However, our results reveal systematic problems with this part of the model, specifically with the tangibles construct and, to a lesser degree, the assurance construct. We also find that the majority of the paths from the five service quality dimensions to satisfaction are not significant. Our recommendation is that the national models either employ the overall product and/or service quality constructs (as used in the ACSI and ECSI models), or build more industry or firm-specific drivers of satisfaction (following Johnson \& Gustafsson, 2000).

Overall, however, our results are quite promising. The pure price construct functioned as anticipated with respect to both satisfaction and loyalty. Cumulative satisfaction was found to update corporate image, which in turn impacts customer loyalty. Cumulative satisfaction is also an antecedent to relational commitment, which in turn has a relatively large impact on customer loyalty. As a result, the new NCSB model explains significantly more variance in loyalty than other national index models and can serve as a basis for future national index models. One potential limitation of our study is that it was based on data from a small economy. However, Norway is known to have a very open and competitive economy making it a good context to test the proposed model. But going forward, it will be important to test the new model in a wider range of both industries and countries. 


\section{References}

1. Anderson, E. W., Fornell, C., \& Rust, R. T. (1997). Customer satisfaction, productivity and profitability: Differences between goods and services. Marketing Science, 16, 129-145.

2. Andreassen, T. W., \& Lervik, L. (1999). Perceived relative attractiveness today and tomorrow as predictors of future repurchase intention. Journal of Service Research, 2, 164-172.

3. Andreassen, T. W., \& Lindestad, B. (1998a). The effects of corporate image in the formation of customer loyalty. Journal of Service Marketing, 1, 82-92.

4. Andreassen, T. W., \& Lindestad, B. (1998b). Customer loyalty and complex services: The impact of corporate image on quality, customer satisfaction and loyalty for customers with varying degrees of service expertise. International Journal of Service Industry Management, 9, 7-23.

5. Bagozzi, R. P. (1980). Causal models in marketing. New York: Wiley.

6. Bagozzi, R. P. (1992). The self-regulation of attitudes, intentions, and behavior. Social Psychology Quarterly, 55, 178-204.

7. Bagozzi, R. P., (1994). Structural equation models in marketing research: Basic principles. In R. P. Bagozzi (Ed.), Principles of marketing research (pp. 317-385). Cambridge, MA: Blackwell.

8. Bagozzi, R. P., \& Yi, Y., (1994). Advanced topics in structural equation models. In R. P. Bagozzi (Ed.), Advanced methods of marketing research (pp. 1-52). Cambridge, MA: Blackwell.

9. Berry, L. L., (1983). Relationship marketing. In L. L. Berry, L. G. Shostack, \& G. D. Upah (Eds.), Emerging perspectives on service marketing (pp. 25-28). Chicago, IL: American Marketing Association.

10. Bloemer, J. M. M., \& Kasper, H. D. P. (1995). The complex relationship between consumer satisfaction and brand loyalty. Journal of Economic Psychology, 16, 311-329.

11. Boulding, W., Kalra, A., Staelin, R., \& Zeithaml, V. A. (1993). A dynamic process model of service quality: From expectations to behavioral intentions. Journal of Marketing Research, 30, 7-27.

12. Bolton, R. N. (1999). A dynamic model of the duration of the customer's relationship with a continuous service provider: The role of satisfaction. Marketing Science, 17, 45-65.

13. Brandsford, J. D., \& Franks, J. J. (1971). The abstraction of linguistic ideas. Cognitive Psychology, 2, 331- 350.

14. Brandsford, J. D., \& Johnson, M. K. (1972). Contextual prerequisites for understanding: Some investigations of comprehension and recall. Journal of Verbal Learning and Verbal Behavior, 11, 717- 726.

15. De Ruyter, K., Bloemer, J., \& Peeters, P. (1997). Merging service quality and service satisfaction: An empirical test of an integrative model. Journal of Economic Psychology, 18, 387-406. 
16. Downey, R. G., \& King, C. V. (1998). Missing data in Likert ratings: A comparison of replacement methods. Journal of General Psychology, 125, 175-191.

17. Deming, W. E., (1981). Management of statistical techniques for quality and productivity. New York University, Graduate School of Business, New York.

18. Edvardsson, B., Johnson, M. D., Gustafsson, A., \& Strandvik, T. (2000). The effects of satisfaction and loyalty on profits and growth: Products versus services. Total Quality Management, 11 (7), 917-927.

19. Eklof, J. A., (2000). European customer satisfaction index pan-European telecommunication sector report based on the pilot studies 1999. Stockholm, Sweden: European Organization for Quality and European Foundation for Quality Management.

20. Emery, F., (1969). Some psychological aspects of price. In B. Taylor, \& G. Wills (Eds.), Pricing strategy (pp. 98-111). London: Staples Press.

21. Feldman, J., \& Lynch, J. G. (1988). Self-generated validity and other effects of measurement on belief, attitude, intention, and behavior. Journal of Applied Psychology, 73, 421-435.

22. Fishbein, M., \& Ajzen, I. (1975). Belief, attitude, intention, and behavior: An introduction to theory and research. Reading, MA: Addison-Wesley.

23. Fornell, C. (1992). A national customer satisfaction barometer: The Swedish experience. Journal of Marketing, 56, 6-21.

24. Fornell, C., \& Cha, J., (1994). Partial least squares. In R. P. Bagozzi (Ed.), Advanced methods of marketing research (pp. 52-78). Cambridge, MA: Blackwell.

25. Fornell, C., Johnson, M. D., Anderson, E. W., Cha, J., \& Bryant, B. E. (1996). The American customer satisfaction index: Nature, purpose and findings. Journal of Marketing, 60, 7-18.

26. Gerstner, E. (1985). Do higher prices signal higher quality? Journal of Marketing Research, 22, 209-215.

27. Gronroos, C. (1990). Service management and marketing: Managing the moments of truth in service competition. Lexington, MA: Lexington Books.

28. Gustafsson, A., \& Johnson, M. D. (1997). Bridging the quality-satisfaction gap. Quality Management Journal, 4, 27-43.

29. Hackl, P., Scharitzer, D., \& Zuba, R. (1996). The Austrian Customer Satisfaction Barometer (ACSB): A pilot study. Der Markt, 35, 86-94.

30. Hart, C. W., \& Johnson, M. D. (1999). Growing the trust relationship. Marketing Management, $8,25-36$.

31. Heskett, J. L., Sasser, Jr., W. E., \& Hart, C. W. (1990). Service breakthroughs: Changing the rules of the game. New York: The Free Press.

32. Hirschman, A. O. (1970). Exit, voice, and loyalty - responses to decline in firms, organizations, and states. Cambridge, MA: Harvard University Press.

33. Huff, L., Fornell, C., \& Anderson, E. (1996). Quality and productivity: Contradictory and complementary. Quality Management Journal, 4, 22-39. 
34. Johnson, M. D., Anderson, E. W., \& Fornell, C. (1995). Rational and adaptive performance expectations in a customer satisfaction framework. Journal of Consumer Research, 21, 128-140.

35. Johnson, M. D., \& Fornell, C. (1991). A framework for comparing customer satisfaction across individuals and product categories. Journal of Economic Psychology, 12, 267-286.

36. Johnson, M. D., \& Gustafsson, A. (2000). Improving customer satisfaction, loyalty and profit: An integrated measurement and management system. San Francisco, CA: Jossey-Bass.

37. Johnson, M. D., Nader, G., \& Fornell, C. (1995). Expectations, perceived performance, and customer satisfaction for a complex service, the case of bank loans. Journal of Economic Psychology, 17, 163-182. Jones, T.O., Sasser, W.E., Jr. (1995). Why satisfied customers defect. Harvard Business Review 73, pp. 88-99.

38. Joreskog, K. G. (1970). A general method for analysis of covariance structures. Biometrika, 57, 239-251.

39. Juran, J. M., \& Gryna, F. M. (1988). Juran's quality control handbook (4th ed). New York: McGraw-Hill. Kumar, N. J., \& Hibbard, J. D., Stern, L. W., (1994). An emperical assessment of the nature and consequences of marketing channel intermediary commitment, M SI report (pp. 94-115). Cambridge, MA: Marketing Science Institute.

40. Mayhew, G. E., \& Winer, R. S. (1992). An empirical analysis of internal and external reference prices using scanner data. Journal of Consumer Research, 19, 62-70.

41. Meyer, A. (1994). Das Deutsche Kundenbarometer, 1994. Ludwig-Maximilians-Universitat Munchen, Munich.

42. Meyer, J. P., \& Allen, N. J. (1984). Testing the side-bet theory of organizational commitment: Some methodological considerations. Journal of Applied Psychology, 69, 372-378.

43. Mittal, V., Ross, W. T., \& Baldasare, P. M. (1998). The asymmetric impact of negative and positive attribute-level performance on overall satisfaction and repurchase intentions. Journal of Marketing, 62, 33-47.

44. Monroe, K. B. (1973). Buyers' subjective perceptions of price. Journal of Marketing Research, $10,70-80$.

45. Oliver, R. L. (1980). A cognitive model of the antecedents and consequences of satisfaction decisions. Journal of Marketing Research, 17, 460-469.

46. Oliver, R. L. (1993). Cognitive, affective, and attribute bases of the satisfaction response. Journal of Consumer Research, 20, 418-430.

47. Oliver, R. L. (1997). Satisfaction: A behavioral perspective on the consumer. New York: McGraw-Hill.

48. Parasuraman, A., Zeithaml, V. A., \& Berry, L. L. (1988). SERVQUAL: A multiple-item scale for measuring consumer perceptions of service quality. Journal of Retailing, 64, 12-40.

49. Poiesz, T. B. C., \& von Grumbkow, J., (1988). Economic well-being, job satisfaction, income evaluation and consumer satisfaction: An integrative attempt. In W. F. Van Raaij, G. M. Van Veldhoven, \& K.-E. Warneryd (Eds.), Handbook of economic psychology (pp. 570593). Dordrecht, Netherlands: Kluwer. 
50. Rust, R., Zahorik, A. J., \& Keiningham, T. L. (1995). Return on quality (ROQ): Making service quality financially accountable. Journal of Marketing, 59, 58-70.

51. Rust, R. T., Inman, J. J., Jia, J., \& Zahorik, A. (1999). What you don't know about customerperceived quality: The role of customer expectation distributions. Marketing Science, 18, 77-92.

52. Samuelsen, B. M., (1997). Kundelojalitet: Aarsaker og effekter (customer loyalty: Causes and effects). Post graduate thesis, Buskerud College.

53. Samuelsen, B. M., \& Sandvik, K. (1997). The concept of customer loyalty. In: Proceedings of the 25th EMAC conference. UK: University of Warwick.

54. Selnes, F. (1993). An examination of the effect of product performance on brand reputation, satisfaction and loyalty. European Journal of Marketing, 27, 19-35.

55. Simon, H. A., (1978). Behavioral research: Theory and public policy. In: The 1979 founders symposium, the Institute for Social Research. Institute for Social Research, Ann Arbor, MI: University of Michigan, pp. 11-35.

56. Simon, J. L. (1974). Interpersonal welfare comparisons can be made and used for redistribution decisions. Kyklos, 27, 63-98.

57. Simmons, C. J., Bickart, B. A., \& Lynch, J. G. (1993). Capturing and creating public opinion in survey research. Journal of Consumer Research, 20, 316-329.

58. Smith, A. K., Bolton, R. N., \& Wagner, J. (1999). A model of customer satisfaction with service encounters involving failure and recovery. Journal of Marketing, 36, 356-372.

59. Steenkamp, J.-B.E.M., \& van Trijp, H. C. M. (1996). Quality guidance: A consumer-based approach to food quality improvement using partial least squares. European Review of Agricultural Economics, 23, 195-215.

60. Warneryd, K.-E. (1988). Economic psychology as a field of study. In W. F. Van Raaij, G. M. Van Veldhoven, \& K.-E. Warneryd (Eds.), Handbook of economic psychology. Dordrecht, The Netherlands: Kluwer Academic Publishers, pp. 2-41.

61. Winer, R. S. (1986). A reference price model of brand choice for frequently purchased products. Journal of Consumer Research, 13, 250-256.

62. Wold, H., (1982). Systems under indirect observation using PLS. In C. Fornell (Ed.), A second generation of multivariate analysis: Methods (pp. 325-347). New York: Praeger.

63. Yi, Y., (1991). A critical review of customer satisfaction. In V. Zeithaml (Ed.), Review of marketing, 1990 (pp. 68-123). Chicago: American Marketing Association.

64. Zeithaml, V. A., Parasuraman, A., \& Berry, L. L. (1990). Delivering quality service: Balancing customer perceptions and expectations. New York: Free Press.

65. Zeithaml, V. A., Parasuraman, A., \& Berry, L. L. (1996). The behavioral consequences of service quality. Journal of Marketing, 6, 31-46. 